\title{
Dansyl - Substituted Aza Crown Ethers: Complexation with Alkali, Alkaline Earth Metal Ions and Ammonium
}

\author{
Nelly Mateeva (Corresponding author) \\ Department of Chemistry, Florida A\&M University, 444 Gamble St. \#204, Tallahassee, FL 32307, USA \\ Tel: 1-850-412-5662Ｅ-mail: nelly.mateeva@famu.edu \\ Shihab Deiab \\ Department of Chemistry, Florida A\&M University, 444 Gamble St. \#204, Tallahassee, FL 32307, USA
}

Tel: 1-850-412-5662Ｅ-mail: diab_pd@yahoo.com

Edikan Archibong

Department of Chemistry, Florida A\&M University, 444 Gamble St. \#204, Tallahassee, FL 32307, USA

Tel: 1-850-412-5662 E-mail: edikan18@yahoo.com

Donka Tasheva

Department of Chemistry, University of Sofia, 1 James Bourchier Ave. 1164 Sofia Bulgaria

Tel: 011-359-2-8161-303 E-mail: dtasheva@chem.uni-sofia.bg

Bereket Mochona

Department of Chemistry, Florida A\&M University, 444 Gamble St. \#204, Tallahassee, FL 32307, USA

Tel: 1-850-599-3285Ｅ-mail: bereket.mochona@famu.edu

Madhavi Gangapuram

College of Pharmacy and Pharmaceutical Sciences, Florida A\&M University

1415 S. Marthin L.King, Jr. Blvd., Tallahassee, FL 32307, USA

Tel: 1-850-561-2200 E-mail: madhavi.gangapuram@famu.edu

Kinfe Redda

College of Pharmacy and Pharmaceutical Sciences, Florida A\&M University

1415 S. Marthin L.King, Jr. Blvd., Tallahassee, FL 32307, USA

Tel: 1-850-561-2200Ｅ-mail: kinfe.redda@famu.edu

The research is financed by Title III and RCMI Programs at Florida A\&M University.

\begin{abstract}
The present study investigates the binding properties of four dansyl substituted aza-crown ethers with alkali, alkaline earth metal ions and ammonium. The influence of the solvent polarity and protonation on the photophysical properties of the compounds was studied by UV/Vis and fluorescence methods. The host species caused only slight changes on the absorption spectra of the ligands. The fluorescence changes were more pronounced and concentration dependent thus allowing to calculate the binding constants of the process. The most stable complex under our working conditions was the one between $\mathrm{Ba}^{2+}$ and DNS18C6.
\end{abstract}

Keywords: Aza-crown ethers, Complexation, Metal ions, Fluorescence, Absorption 


\section{Introduction}

Dansyl chloride is a reagent very often used to react with primary and secondary amines in order to introduce a fluorescent moiety in a molecule. Amino acid derivatization is widely employed in HPLC chromatography in order to identify the $\mathrm{N}$ - terminal residue of peptides and proteins as well as to utilize a fluorescent detector for amino acid separation.

A typical example for the above mentioned method is shown in [Wang, Y., 2007]. An accurate, simple, and sensitive reversed-phase high-performance liquid chromatographic method, with loratadine as internal standard (IS) and UV detection at $286 \mathrm{~nm}$, has been developed for determination of cystine in human urine. Amino acids fluorescently tagged with dansyl chloride were used in capillary electrophoresis study of amino acid separation. [Yin, D., 2008]

In molecular recognition chemistry, labeling of either guest or the host is often needed in order to create a chemosensor for detection of the investigated phenomena.

Modified cyclodextrins bearing fluorescent moieties have been used by Ueno and coworkers [Ueno, A., 1999] as sensors for a wide variety of organic guests, including chiral molecules. Roper et al., [Roper, E.D., 2007] reported a fluorogenic derivative of 1,3-alternate calix[4]arenebis- (crown-6) containing a dansyl group in the protonionizable side arm has been employed in selective sensing of $\mathrm{Tl}^{+}$and $\mathrm{Cs}^{+}$at low concentration levels in $\mathrm{MeCN}-\mathrm{H}_{2} \mathrm{O}(1: 1)$ mixed solvent.

Recognition and sensing of heavy and transition metal ions via artificial receptors are of current interest in supramolecular chemistry because of their significant importance in chemical, biological, and environmental assays. Of particular interest in this regard are fluorescent sensors, because they have both high sensitivity and ease of signal transduction. A practical fluorescent sensor for targeting ions of specific importance should at least have the following properties: simplicity, high selectivity, strong signal output, wide conditions of coordination and recognition in aqueous environments. Chen et al. [2004] reported a new fluorescent chemosensor for $\mathrm{Hg}^{2+}$ based on a dansyl amide-armed calix[4]-aza-crown. It exhibits high sensitivity and selectivity toward $\mathrm{Hg}^{2+}$, and the detection limit for $\mathrm{Hg}^{2+}$ was found to be $4.1 \times 10^{-6} \mathrm{~mol} / \mathrm{L}$. [Chen, Q.-Y., 2004] More applications involving calixarines as well as peptide synthesis were reported elsewhere. [Casnati, A., 2001; Ten Brink H. T., 2006]

To the best of our knowledge, there are only a few examples of dansyl-modified crown ethers. Tsunooka et al. [1997] described the synthesis and cation-binding behavior of anionic polymers bearing both crown ether units and dansyl units. The structure of the anionic moieties in polymers strongly affects the cation-responsive fluorescence. [Shirai, M., 1997]

Ossowski et al., investigated the influence of alkaline, alkaline earth metal ions as well as number of heavy metals ions on the spectroscopic properties of the dansyl group covalently linked to crown ether or diazacrown ethers. Interaction of the alkali metal ions with all fluoroionophores studied was weak, while alkaline earth metal ions interact strongly causing about $50 \%$ quenching of dansyl fluorescence. The $\mathrm{Cu}^{2+}, \mathrm{Pb}^{2+}$ and $\mathrm{Al}^{3+}$ cations interact very strongly with dansyl chromophore regardless of the crown ether type, causing a major change in absorption spectrum of the chromophore and forming non-fluorescent complexes. The $\mathrm{Co}^{2+}, \mathrm{Ni}^{2+}, \mathrm{Zn}^{2+}, \mathrm{Mg}^{2+}$ and $\mathrm{Ag}^{+}$cations interact moderately with all fluoroionophores studied causing about $20 \%$ of fluorescence quenching of dansyl. The quenching efficiency of didansylated fluoroionophores by the alkali metal ions and alkaline earth metal ions is weaker than monodansylated ones. [Warmke, H., 2000; Sulowska, H., 2002]

In earlier studies we investigated the synthesis and complexation properties of aza-crown ether containing chromoand fluoroionophores where the complexation was done in excess of the guest and in anhydrous solvents [Mateeva, N., 1994; Mateeva, N., 1995; Antonov, L., 1996]

In the present study we utilized four dansyl aza-crown ether derivatives and quantified their binding properties with alkaline, alkaline earth metal ions and ammonium. We report the binding constants and spectroscopic changes accompanying the complexation process.

\section{Experimental}

\subsection{Materials and Methods}

All chemicals were purchased from Sigma Aldrich and were ACS grade. They were used without further purification. Melting points were determined on Mel Temp 3.0 instrument and were uncorrected. ${ }^{1} \mathrm{H}$ NMR spectra were recorded on a Varian Gemini $\mathrm{HX} 300 \mathrm{MHz}$ spectrometer using $\mathrm{CDCl}_{3}$ as a solvent and the chemical shifts are expressed in parts per million $(\delta, \mathrm{ppm})$ downfield from TMS as an internal standard. Infrared spectra (IR) were recorded, for $\mathrm{KBr}$ discs, on a Perkin-Elmer FTIR 1430 spectrometer. Elemental analyses were performed for C, H, 
and N (Galbraith Laboratories, Inc., Knoxville, TN, USA) and were within $\pm 0.4 \%$ of the theoretical values. The UV/Vis absorption of the solutions was measured using the Shimadzu UV-2401 PC spectrophotometer instrument. Fluorescence measurements were done on the Perkin Elmer LS55 Fluorescence spectrofluorimeter.

\subsection{Synthesis}

The compounds utilized in this study were synthesized according to Ossowski et al [Warmke, H., 2000; Sulowska, H., 2002]. The proton NMR, IR data and elemental analysis confirm the structure and are also in agreement with published data.

Figure 1 shows the structures of the aza-crown ether derivatives used in this study.

DNS2N218C6: ${ }^{1} \mathrm{H}$ NMR $\left(\mathrm{CDCl}_{3}\right) 2.85$ (s, 6H, $\left.\mathrm{CH}_{3}\right) ; 3.45-3.55$ (m, 24H, crown); 7.17 (d, 1H, J = 7.8 Hz, Ar H); $7.40(\mathrm{dd}, 1 \mathrm{H}, \mathrm{J} 1=8.0 \mathrm{~Hz}, \mathrm{Ar} \mathrm{H})$;

$7.50(\mathrm{dd}, 1 \mathrm{H}, \mathrm{J} 1=8.2 \mathrm{~Hz}, \mathrm{Ar} \mathrm{H}) ; 8.10(\mathrm{~d}, 1 \mathrm{H}, \mathrm{J}=8.2 \mathrm{~Hz}, \operatorname{Ar~H}) ; 8.20(\mathrm{~d}, 1 \mathrm{H}, \mathrm{J}=8.7 \mathrm{~Hz}, \mathrm{Ar} \mathrm{H}) ; 8.45(\mathrm{~d}, 1 \mathrm{H}, \mathrm{J}=$ $8.9 \mathrm{~Hz}, \mathrm{Ar} \mathrm{H})$.

IR: $\left(v \mathrm{~cm}^{-1}\right)$ : $(\mathrm{KBr}): 2820-2950,1620,1550,1150$

Elemental analysis: $\left(\mathrm{C}_{24} \mathrm{H}_{37} \mathrm{~N}_{3} \mathrm{O}_{6} \mathrm{~S}\right)$ : (\%calculated/found): C:58.16/58.25; H:7.52/7.20; N: 8.48/8.75

DNSN218C6: ${ }^{1} \mathrm{H}$ NMR $\left(\mathrm{CDCl}_{3}\right) 2.85\left(\mathrm{~s}, 12 \mathrm{H}, \mathrm{CH}_{3}\right) ; 3.45-3.55$ (m, 24H, crown); 7.16 (d, 2H, J = 7.8Hz, Ar H); $7.45(\mathrm{dd}, 2 \mathrm{H}, \mathrm{J}=8.0 \mathrm{~Hz}, \mathrm{Ar} \mathrm{H}) ; 7.54(\mathrm{dd}, 2 \mathrm{H}, \mathrm{J}=7.8 \mathrm{~Hz}, \operatorname{Ar~H}) ; 8.18(\mathrm{~d}, 2 \mathrm{H}, \mathrm{J}=6.3 \mathrm{~Hz}, \operatorname{Ar~H}) ; 8.20$ ( d, 2H, J = 8.7 $\mathrm{Hz}, \mathrm{Ar} \mathrm{H}) ; 8.49$ (d, 2H, J = 8.1 Hz, Ar H ).

IR: $\left(v \mathrm{~cm}^{-1}\right):(\mathrm{KBr}): 2830-2970,1610,1544,1160$

Elemental analysis: $\left(\mathrm{C}_{36} \mathrm{H}_{48} \mathrm{~N}_{4} \mathrm{O}_{8} \mathrm{~S}_{2}\right)$ : (\%calculated/found): C:59.32/59.45, H: 6.64/6.75, N: 7.69/7.30

DNS15C5: ${ }^{1} \mathrm{H}$ NMR $\left(\mathrm{CDCl}_{3}\right) 2.85$ (s, 6H, $\left.\mathrm{CH}_{3}\right) ; 3.40-3.55$ (m, 20H, crown); 7.20 (d, 1H, J = 7.15 Hz, Ar H); 7.50 (dd, $1 \mathrm{H}, \mathrm{J}=8.7 \mathrm{~Hz}, \mathrm{Ar} \mathrm{H}) ; 7.57$ (dd, 1H, J= 8.4 Hz, Ar H); 8.10 (d, 1H, J = 8.4 Hz, Ar H); 8.35 (d, 1H, J = 8.4 Hz, Ar H); 8.52 ( d, 1H, J = 8.1 Hz, Ar H).

IR: $\left(v \mathrm{~cm}^{-1}\right):(\mathrm{KBr}): 2820-2970,1615,1550,1155$

Elemental analysis: $\left(\mathrm{C}_{22} \mathrm{H}_{32} \mathrm{~N}_{2} \mathrm{O}_{6} \mathrm{~S}\right)$ : (\%calculated/found), C: 58.39/58.45, H: 7.13/7.25, N: 6.19/6.30

DNS18C6: ${ }^{1} \mathrm{H}$ NMR $\left(\mathrm{CDCl}_{3}\right) 2.90$ (s, 6H, $\left.\mathrm{CH}_{3}\right) ; 3.50-3.65$ (m, 24H, crown); 7.26 (d, 1H, J = 8.8, Ar H) 7.50 (dd, $1 \mathrm{H}, \mathrm{J}=8.7 \mathrm{~Hz}, \mathrm{Ar} \mathrm{H}) ; 7.57(\mathrm{dd}, 1 \mathrm{H}, \mathrm{J}=8.4 \mathrm{~Hz}, \mathrm{Ar} \mathrm{H}) ; 8.15(\mathrm{~d}, 1 \mathrm{H}, \mathrm{J}=8.3 \mathrm{~Hz}, \mathrm{Ar} \mathrm{H}) ; 8.30(\mathrm{~d}, 1 \mathrm{H}, \mathrm{J}=8.3 \mathrm{~Hz}, \mathrm{Ar}$ $\mathrm{H}) ; 8.52(\mathrm{~d}, 1 \mathrm{H}, \mathrm{J}=8.2 \mathrm{~Hz}, \operatorname{Ar} \mathrm{H})$.

IR: $\left(v \mathrm{~cm}^{-1}\right):(\mathrm{KBr}): 2820-2960,1620,1550,1160$

Elemental analysis: $\left(\mathrm{C}_{24} \mathrm{H}_{36} \mathrm{~N}_{2} \mathrm{O}_{7} \mathrm{~S}\right)$ : (\%calculated/found) C: 58.04/58.25, H: 7.31/7.40, N: 5.64/5.75

\subsection{Spectroscopic Studies}

All crown ether solutions $\left(1-3 \times 10^{-5} \mathrm{M}\right)$ were prepared from a stock solution in acetonitrile (spectroscopic grade, Sigma Aldrich). The solutions of the guest were also prepared in acetonitrile and different volumes were added to the host solutions. The concentration of the DNS crown ethers was kept constant while the concentration of the metal salts was changing. The corresponding volumes of the guest and the host were mixed in $25 \mathrm{~mL}$ volumetric flasks and the volume adjusted to the mark with acetonitrile. All measurements were performed at $25^{\circ} \mathrm{C}$.

\section{Results and Discussion}

\subsection{Protonation of the DNS chromophore. Absorption and fluorescence in presence of $\mathrm{HCl}$ and $\mathrm{H}_{2} \mathrm{O}$}

Addition of hydrochloric acid causes decrease in absorption intensity at both absorption maxima. (Figure 2) This is consistent with protonation at both dimethylamino and macrocyclic nitrogen atom. Addition of hydrochloric acid causes fluorescence quenching at the emission maximum at $520 \mathrm{~nm}$ however no significant shift in the emission maximum wavelength has been observed indicating that the changes are consistent with protonation rather than changing the polarity of the medium. (Figure 3)

\subsection{Effect of cations on the absorption and emission properties of the DNS chromophore}

The complexation properties of the ligands were investigated in acetonitrile. The amount of host was kept constant and the absorption and emission spectra were recorded in presence of increasing amounts of the guest. Metal ions cause only a slight decrease in the absorption intensity $(\Delta \mathrm{A}==0.05-0.1)$ of the charge transfer band combined with a slight hypsochromic shift $(\Delta \lambda=1-5 \mathrm{~nm})$ (Figure 4) 
Metal ions induce slight hypsochromic change and decrease in absorption intensity. Similarly to the previous study on the NBD chromophore [Mateeva, N., 2010] the absorption changes are very small and sometimes inconsistent with the concentration changes of the guest.

The majority of ions studied in this paper caused only minor changes in the molar absorption coefficients of the long- and short-wave absorption bands in the spectrum of dansyl chromophore. Such changes can be explained by the modification of environment polarity caused by the excess salt added and interaction of metal ions with fluoroionophores. The influence of the environment polarity on the absorption and emission spectra of the dansyl chromophore is well known.

A clear trend in the absorption spectra is increase in the absorption maximum at about $260 \mathrm{~nm}$ due to the complex formation. No clear trend however was observed in terms of correlation between ionic size, crown ether size and changes in the absorption spectra.

Upon complex formation a strong fluorescence quenching was observed with all metal ions observed. The dansyl substituted monoaza- crown ethers as well as monosubstituted diaza crown ether derivatives exhibit stronger fluorescence quenching than the disubstituted diaza compound.

Emission spectra of all fluoroionophores studied are typical of dansyl emission in organic solvent with maximum at about $520 \mathrm{~nm}$. Incorporation of the ionophore moiety does not change the shape and position of dansyl amide fluorescence spectrum. An addition of metal ions causes the decrease of dansyl fluorescence intensity and simultaneously a small batochromic shift of the fluorescence spectrum compared to the free ligand as shown in for different fluoroionophores. (Figure 5)

Quenching efficiency of metal ions studied depends on the kind of metal ion as well as the properties of macro-cycle moiety: cavity size, number of nitrogen atoms and number of dansyl substituents. The quenching efficiency of other ions depends on the size of macrocyclic moiety, as well as on the atomic radius of the metal.

For ions $\mathrm{Li}^{+}, \mathrm{Na}^{+}, \mathrm{K}^{+}$, and $\mathrm{Mg}^{2+}$ only a weak quenching of dansyl fluorescence (not higher than a several percent) is observed. Generally the quenching is higher for monodansylated macrocycle than didansylated ones. Double-charged ions exhibited much stronger binding than the single charged; however, $\mathrm{K}^{+}$seems to have much stronger affinity toward DNS18C6 compared to the other investigated compounds. (Tables $1 \& 2$ ).

The calculation of the binging constants was performed on the basis of the fluorescence spectra of the ligands and complexes similarly to the calculations performed for the corresponding NBD substituted compounds [Mateeva, N., 2010]. The results are summarized in Tables $1 \& 2$.

The complexation process can be described by the following:

$$
\begin{aligned}
& \mathrm{M}+\mathrm{L} \rightarrow \mathrm{ML} \\
& \frac{I_{0}}{I_{0}-I}=\frac{a}{K_{f} M}+a
\end{aligned}
$$

The apparent formation constant $K_{f}$ was calculated according to Valeur et al [Valeur, B, 2002] using the equation (1) where $a$ is a constant incorporating the factors of molar absorptivities and fluorescence quantum yields for the free ligand and complex. $C_{\mathrm{M}}$ and $C_{1}$ are the concentrations of the metal ion and the ligand. Under the conditions of $C_{\mathrm{M}} \gg C_{1}$ and hence, $[\mathrm{M}] \sim C \mathrm{M}$, a plot of $I_{0} /\left(I-I_{0}\right)$ versus $1 / C_{\mathrm{M}}$ is linear, and $K_{\mathrm{f}}$ is found as a ratio of the intercept at the $\mathrm{OY}$ axis and the slope.

From the data shown in Tables 1 and 2 it can be seen that 18-crown- 6 containing compounds form stronger complexes than the 15 -crown-5 analogs. Alkaline earth metal ions form more stable complexes than the alkaline metal ions. The effect is due from one side, to the higher charge and from another, to the closeness in size to the ligand cavity. Exception is potassium complexation with DNS18C6 which is related probably to better size fit to the size of the crown cavity. The data for magnesium complexation were inconsistent due probably to the presence of more than one equilibrium in the solution.

There is not enough evidence in the literature to support the actual participation of the dansyl chromophore in the complexation. We assume that the function of the dansyl moiety in this study is to only detect the binding process due to the changes in its fluorescent characteristics.

\section{Conclusions}

DNS modified crown ethers were synthesized, purified and their structure confirmed by proton NMR, IR and elemental analysis. Absorption spectra were only slightly affected by the presence of the hosts, however, fluorescence changes were significant and concentration dependant. Double charged ions exhibited higher affinity 
toward 18C6 containing ligands and the strongest binding was between $\mathrm{Ba}^{2+}$ and DNS18C6. The similarity of the crown ether cavity and the size of the $\mathrm{K}^{+}$ion is probably the reason for the greater stability of this complex compared to the other single charged ions.

\section{References}

Antonov, L., Mateeva, N., Mitewa, M., \& Stoyanov, St. (1996). Spectral properties of aza-15-crown-5 containing styryl dyes. Dyes and Pigments, 30, 235-243.

Casnati, A., Giunta, F., Sansone, F., Ungaro, R., Montalti, M., Prodi, L., \& Zaccheroni, N. (2001). Synthesis, complexation and photophysics of 1,3-alternate calix[4]arene-crowns-6 bearing fluorophoric units on the bridge. Supramolecular Chemistry, 13, 419-434.

Chen, Q.-Y., \& Chen, C.-F. (2004). A new $\mathrm{Hg}^{2+-}$ selective fluorescent sensor based on a dansyl amide-armed calix[4]-aza-crown. Tetrahedron Letters, 46, 165-168.

Mateeva, N., Deiab, S., Archibong, E., Jackson, M., Mochona, B., Gangapuram, M., \& Redda, K. (2010). N-(4-amino-7-nitrobenzaoxa-1,3-diazole) - Substituted Aza Crown Ethers: Complexation with Alkali, Alkaline Earth Metal Ions and Ammonium. J. Inclus. Phenom. Macromol. Chem., in press.

Mateeva, N., Deligeorgiev, T., Mitewa, M., Simova, S., \& Dimov, I. (1994). Synthesis and Spectral Properties of New Benzothiazolic Chromofluoroionophore Containing Aza-18-Crown-5 Macrocyclic Moiety. Journal of Inclusion Phenomena and Molecular Recognition in Chemistry, 17, 81-91.

Mateeva, N., Enchev, V., Antonov, L., Deligeorgiev, T., \& Mitewa, M. (1995). Spectroscopic study of the complexation of an aza-15-crown-5 containing chromofluoroionophore with $\mathrm{Ba}^{2+}$ and $\mathrm{Ca}^{2+}$ cations. Journal of Inclusion Phenomena and Molecular Recognition in Chemistry, 20, 323-333.

Roper, E.D., Talanov, V.S., Gorbunova, M.G., Bartsch, R.A., \& Talanova, G. G. (2007). Optical Determination of Thallium(I) and Cesium(I) with a Fluorogenic Calix[4]arenebis(crown-6 ether) Containing One Pendent Dansyl Group. Anal. Chem., 79, 1983-1989.

Shirai, M., Matoba, Y., \& Tsunooka M. (1997). Cation-Responsive Fluorescence Of Dansyl-Labeled Polyanions Bearing Crown Ether Units. Journal of Fluorescence, 7, 245-250.

Sulowska, H., Wiczk, W., Młodzianowski, J., Przyborowska, M., \& Ossowski, T. (2002). Synthesis and fluorescence behavior of crown and azacrown ethers carrying the dansyl fluorophore as a pendant in acetonitrile solution. Journal of Photochemistry and Photobiology A: Chemistry, 150, 249-255.

Ten Brink H. T., Meijer J. T, Geel, R. V, Damen M., Lowik, D. W. P. M., \& van Hest J. C M. (2006). Solid-phase synthesis of C-terminally modified peptides. Journal of peptide science: an official publication of the European Peptide Society, 12, 686-92.

Ueno, A., Ikeda, A., Ikeda, H., Ikeda, T., \& Toda, F. (1999). Fluorescent Cyclodextrins Responsive to Molecules and Metal Ions. Fluorescence Properties and Inclusion Phenomena of N $\alpha$-Dansyl-L-lysine- $\beta$-cyclodextrin and

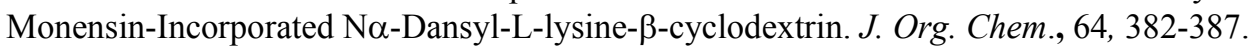

Valeur, B. (2002). Molecular Fluorescence. Principles and Applications. Wiley-VCH: Weinheim, Germany, pp 341-342.

Wang, Y., Kang, X.-J., Wei-Hong Ge, W.-H., Sun, X.-Z., \& Peng, J. (2007). Simple, rapid, and accurate RP-HPLC method for determination of cystine in human urine after derivatization with dansyl chloride. Chromatographia, 65, 527-532.

Warmke, H., Wiczk, W., \& Ossowski, T. (2000). Interactions of metal ions with monoaza crown ethers A15C5 and A18C6 carrying dansyl fluorophore as pendant in acetonitrile solution. Talanta, 52, 449-456.

Yin, D., Xiea, C., Zhanga, L., Liua, B., Zhoua, X., Wang, P., \& Wua, M. (2008). Development of a novel capillary electrophoresis chemiluminescence system for amino acid analysis. Luminescence, 23, 434-438. 
Table 1. Apparent formation constants $K_{f}$ for the complexation between DNS crown ethers, alkaline metal ions and ammonium

\begin{tabular}{|l|l|l|l|l|}
\hline Ion & $\mathrm{Li}^{+}$ & $\mathrm{Na}^{+}$ & $\mathrm{K}^{+}$ & $\mathrm{NH}_{4}^{+}$ \\
\hline Ligand & $K_{f}$ & $K_{f}$ & $K_{f}$ & $K_{f}$ \\
\hline DNS15C5 & 195 & 160 & 41 & 217 \\
\hline DNS18C6 & 98 & 155 & $2.56 \times 10^{4}$ & 412 \\
\hline DNSN218C6 & 9.63 & 24.3 & 350 & 200 \\
\hline DNS2N218C6 & $\mathrm{N} / \mathrm{A}$ & 0.77 & 1.55 & 0.56 \\
\hline
\end{tabular}

Table 2. Apparent formation constants $K_{f}$ for the complexation between DNS crown ethers, and alkaline earth metal ions

\begin{tabular}{|l|l|l|l|l|}
\hline Ion & $\mathrm{Mg}^{2+}$ & $\mathrm{Ca}^{2+}$ & $\mathrm{Sr}^{2+}$ & $\mathrm{Ba}^{2+}$ \\
\hline Ligand & $K_{f}$ & $K_{f}$ & $K_{f}$ & $K_{f}$ \\
\hline DNS15C5 & N/A & 222 & 345 & $1.6 \times 10^{3}$ \\
\hline DNS18C6 & N/A & $2.6 \times 10^{4}$ & $6.4 \times 10^{3}$ & $1.9 \times 10^{5}$ \\
\hline DNSN218C6 & N/A & $3.5 \times 10^{2}$ & $7.5 \times 10^{4}$ & $2.9 \times 10^{3}$ \\
\hline DNS2N218C6 & N/A & 55 & 4.61 & 23 \\
\hline
\end{tabular}
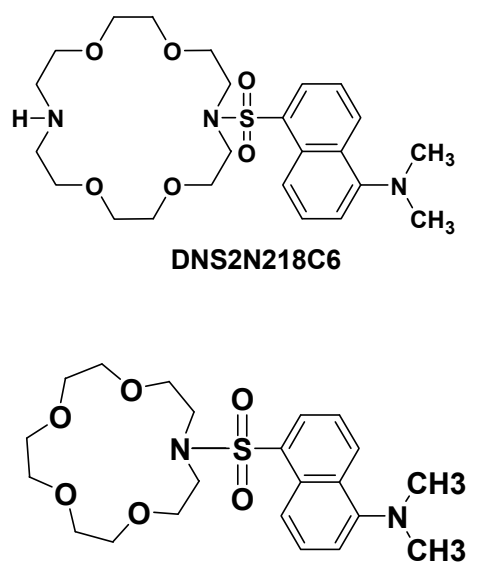

DNS15C5
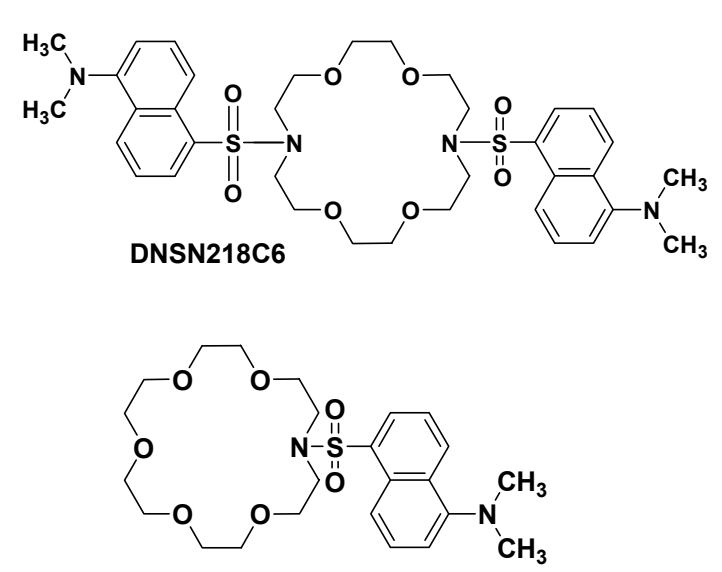

DNS18C6

Figure 1. Dansyl aza-crown ethers used in the study 


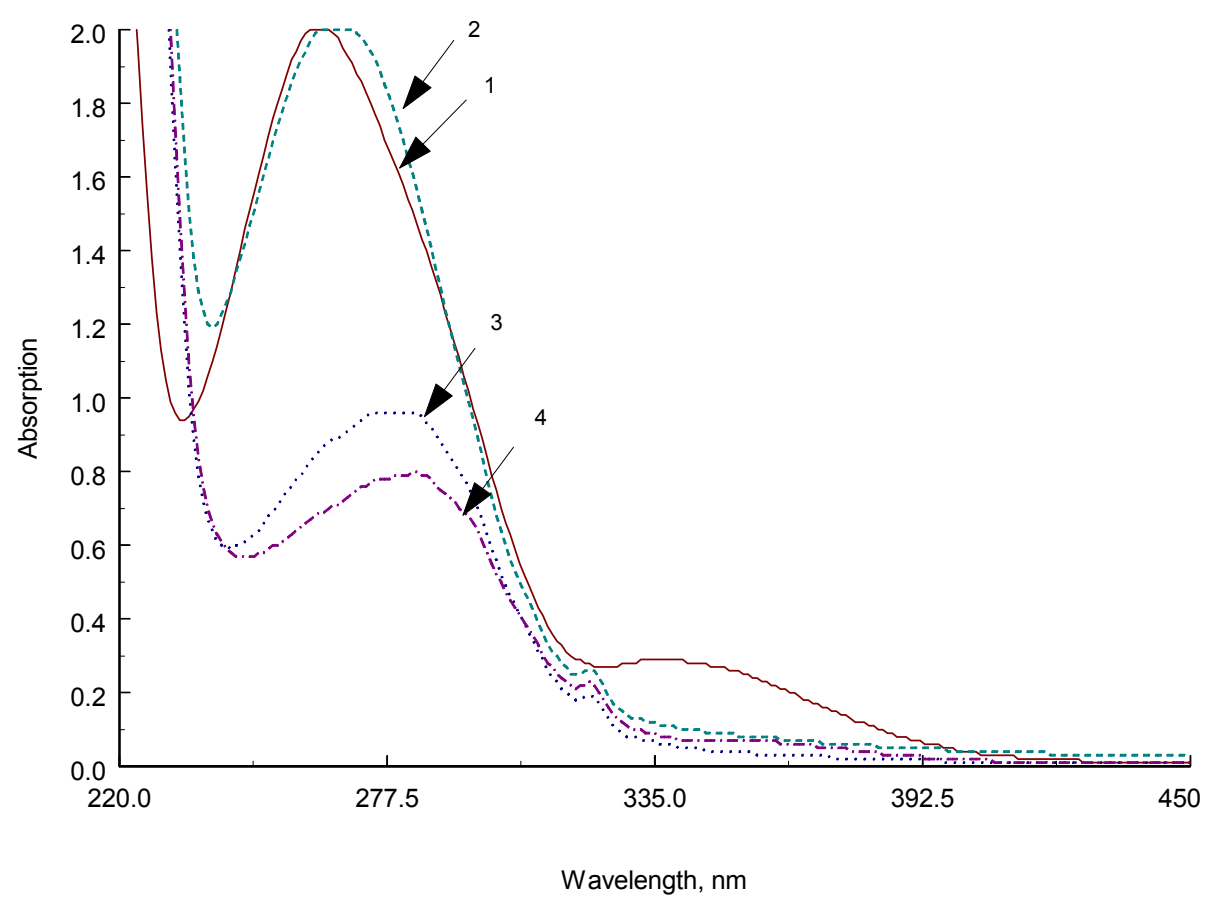

Figure 2. Absorption spectra of DNS18C6 $\left(1.0 \times 10^{-5} \mathrm{M}\right)$ in acetonitrile in presence of increasing amounts of $1.0 \times 10^{-5} \mathrm{M}$ hydrochloric acid $(1 \rightarrow 4)$

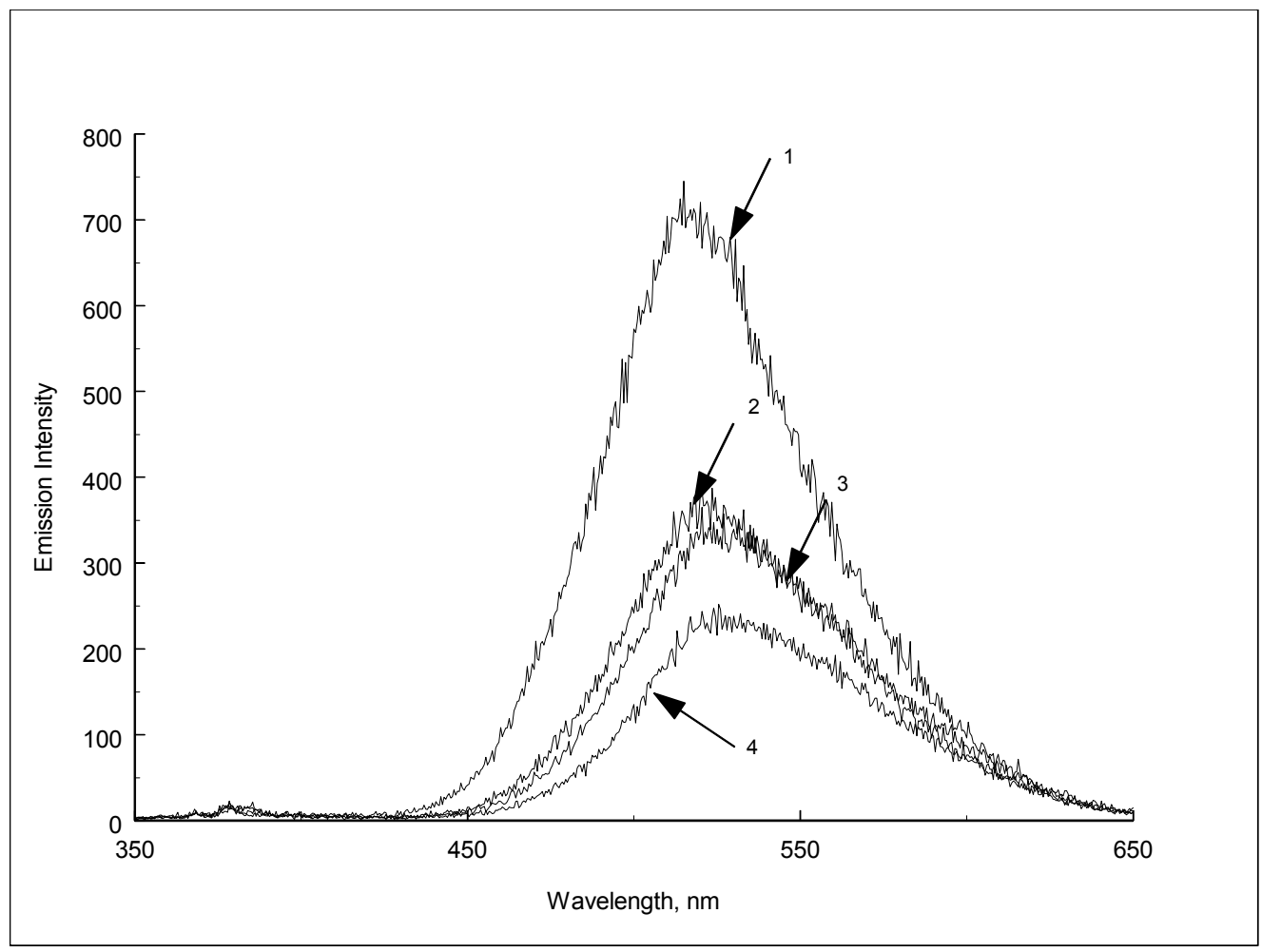

Figure 3. Emission spectra of DNS18C6 $\left(1 \times 10^{-5} \mathrm{M}\right)$ in acetonitrile presence of increasing amounts of $1 \times 10^{-5} \mathrm{M}$ hydrochloric acid $(1 \rightarrow 4)$ 


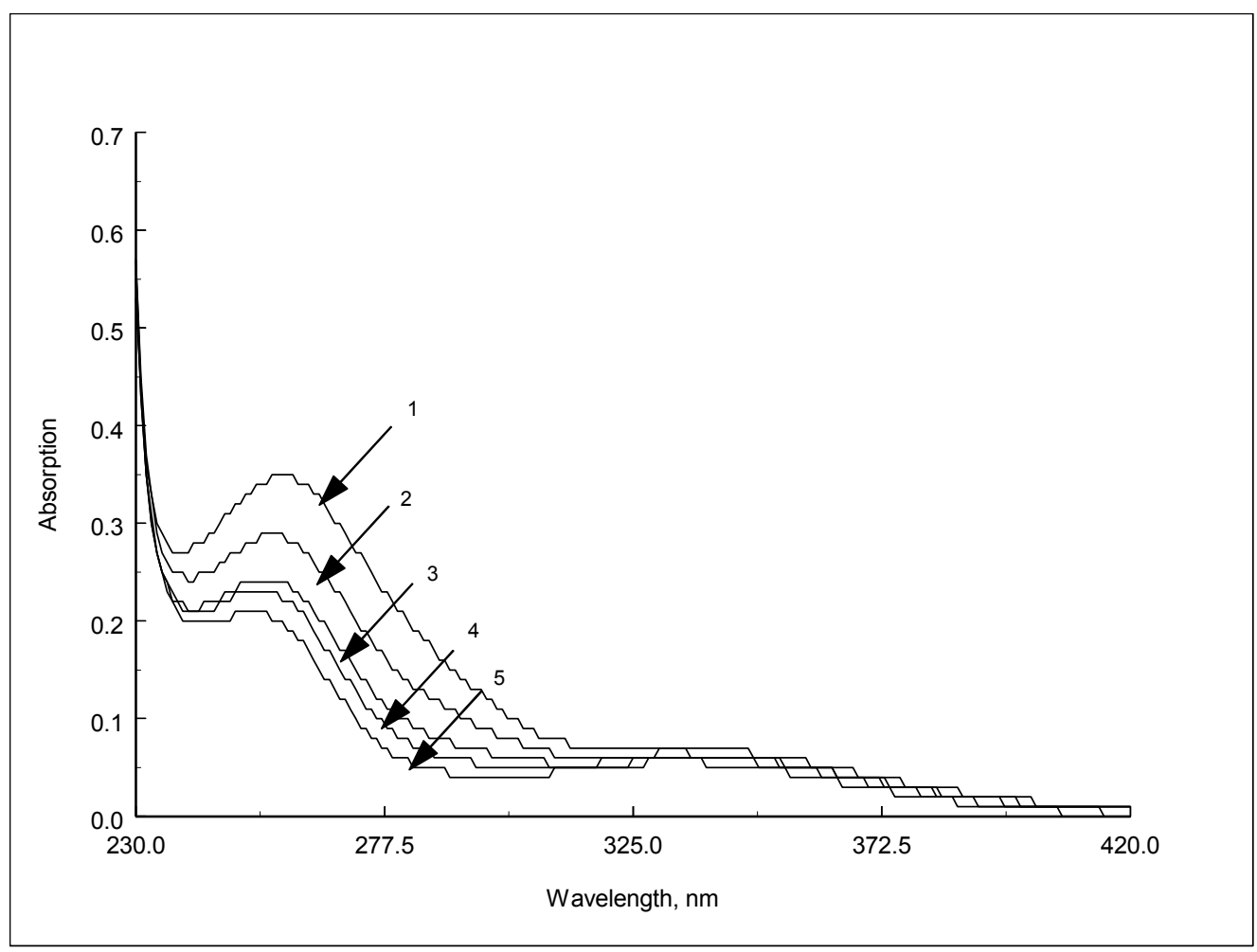

Figure 4. Absorption spectra of DNSN218C6 $\left(1 \times 10^{-5} \mathrm{M}\right)$ in presence of increasing amounts of $1 \mathrm{M} \mathrm{LiClO}_{4}$ in acetonitrile

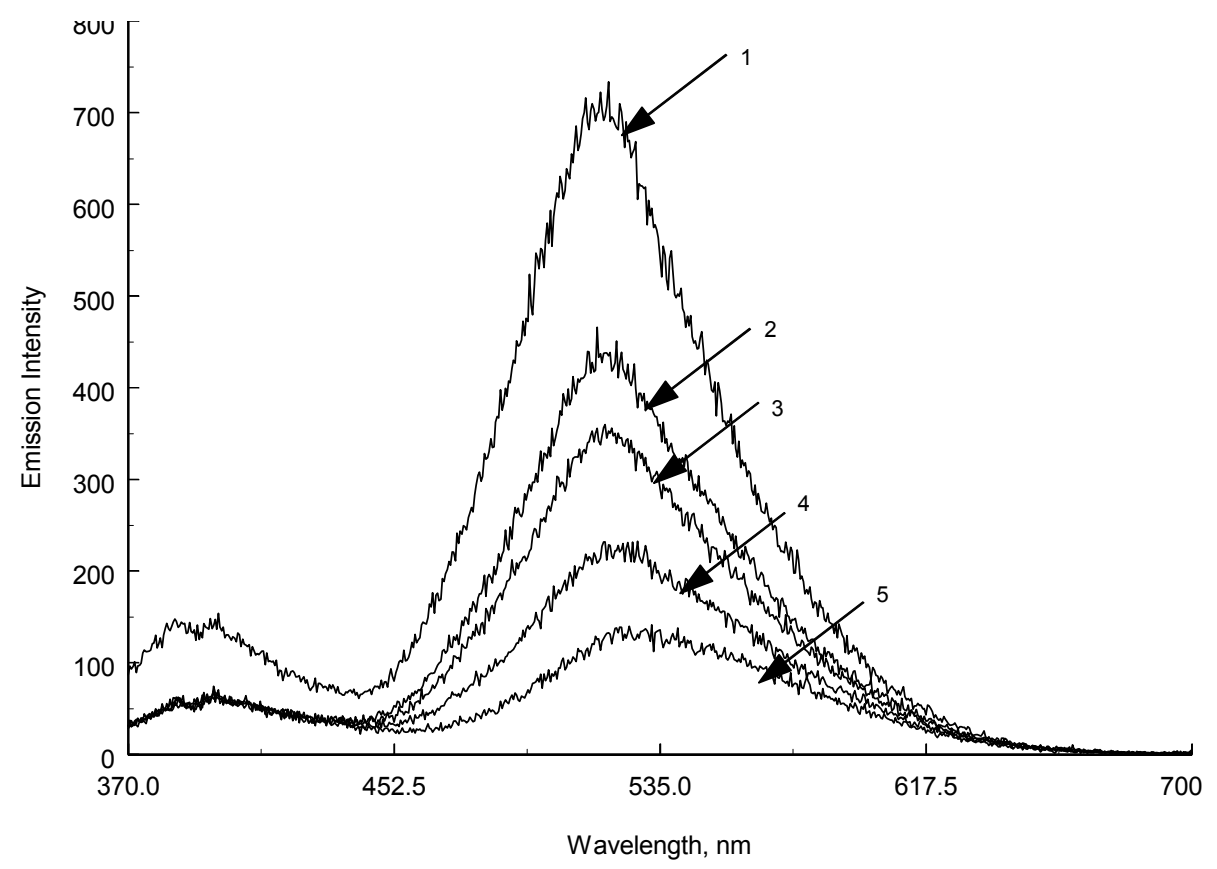

Figure 5. Emission spectra of DNS18C6 $\left(1 \times 10^{-5} \mathrm{M}\right)$ in acetonitrile in presence of increasing amounts $(1 \rightarrow 5)$ of $\mathrm{BaClO}_{4}\left(1 \times 10^{-4} \mathrm{M}\right.$ stock solution $)$ 